Борисов А. А., канд. техн. наук, доцент,

доцент кафедры технологии строительного производства,

Одесская государственная академия строительства и архитектуры,

ул. Дидрихсона, 4, Одесса, 65029

$凶$ etinvest@gmail.com $\approx+38(097) 9756594$

Кирилюк С. В., канд. техн. наук,

зав. лаб. кафедры технологии строительного производства,

Одесская государственная академия строительства и архитектуры,

ул. Дидрихсона, 4, Одесса, 65029

凶kirilstani@ukr.net $5+38(067) 8433770$

Бабий И. Н., канд. техн. наук, доцент,

доцент кафедры технологии строительного производства,

Одесская государственная академия строительства и архитектуры,

ул. Дидрихсона, 4, Одесса, 65029

凶igor7617@gmail.com ※+38(098)2499305

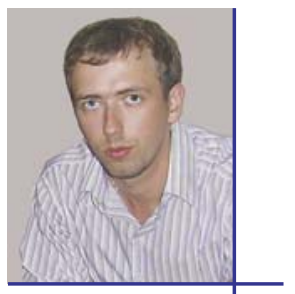

Борисов А. А.

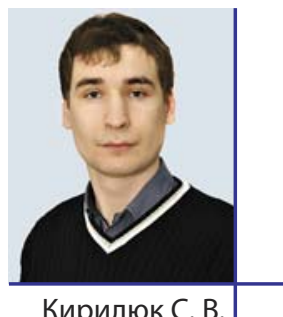

Кирилюк С. В.

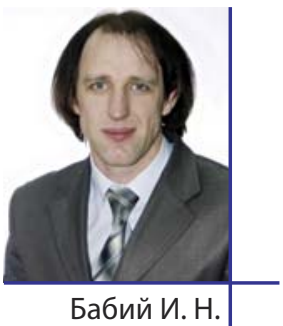

O. Borisov, Cand. Tech. Sciences, assistant professor, assistant professor of technology of building production Odessa State Academy of Building and Architecture, st. Didryhsona, 4, Odessa, 65029

凶 etinvest@gmail.com \& + 38(097)9756594

S. Kyryliuk, Cand. Tech. Sciences,

Head of Laboratory of technology of building production,

Odessa State Academy of Building and Architecture,

st. Didryhsona, 4, Odessa, 65029

凶kirilstani@ukr.net * +38(067)8433770

I. Babiy, Cand. Tech. Sciences, assistant professor,

assistant professor of technology of building production,

Odessa State Academy of Building and Architecture,

st. Didryhsona, 4, Odessa, 65029

凶igor7617@gmail.com +38(098)2499305

\title{
ИССЛЕДОВАНИЕ ПЛАСТИЧЕСКОЙ ПРОЧНОСТИ СОСТАВОВ РАСТВОРА ЗАЩИТНОГО ГРУНТОБЕТОННОГО ЭКРАНА
}

\section{ДОСЛІДЖЕННЯ ПЛАСТИЧНОЇ МІЦНОСТІ СКЛАДІВ РОЗЧИНУ ЗАХИСНОГО ГРУНТОБЕТОННОГО ЕКРАНУ INVESTIGATION OF PLASTIC STRENGTH OF SOLID COMPOSITES OF PROTECTIVE SOIL CONCRETE SCREEN}

Аннотация. Приведена методика проведения экспериментальных исследований. Получены результаты пластической прочности составов раствора, которые в дальнейшем могут быть использованы для составления технологического регламента сооружения защитного ґрунтобетонного экрана под сооружением.

Ключевые слова: пластическая прочность, состав раствора, грунтобетонный экран, пластометр, экспериментальные исследования.

Анотація. Наведено методику проведення експериментальних досліджень. Отримані результати пластичної міцності складів розчину, які в подальшому можуть бути використані для складання технологічного регламенту спорудження захисного ґрунтобетонного екрану під спорудою.

Ключові слова: пластична міцність, склад розчину, грунтобетонний екран, пластометр, експериментальні дослідження.

Annotation. The methodology of the experimental research is given. The results of plastic strength of the compositions of the solution were obtained and described, which can later be used to draw up technological procedures for the construction of a protective concrete screen under the construction.

Key words: plastic strength, mortar composition, soil concrete screen, plastometer, experimental studies.

\section{Введение}

Задача защиты зданий и сооружений от подтопления актуальна уже много десятков лет. Эффективным способом защиты зданий и сооружений от подземных вод является устройство вертикальных противофильтрационных экранов [1]. При недосягаемой глубине водоупорного горизонта может применяться разработанная технология устройства сопряженного защитного грунтобетонного экрана под существующими зданиями и сооружениями с использованием шнекового оборудования [2].

Защитный грунтобетонный экран образуется за счет перемешивания грунта основания с твердеющими растворами. После разработки грунта двунаправленным шнеком, вращаясь в противоположную сторону, транспортирует раствор к центру и одновременно перемешивает существующий грунт. Растворы состоят из цемента и добавок базальтовой фибры, бентонита и жидкого стекла. В результате формируется грунтобетонный экран между направляющими скважинами [3].

\section{Цель исследования}

Провести сравнительный анализ результатов исследования пластической прочности составов раствора для сооружения защитного ґрунтобетонного экрана под сооружением.

\section{Аппаратура, методы и материалы}

Оценка пластической прочности растворных композиций проводилась на пластометре Ребиндера (рис. 1), модернизированном электроприводом. В основе работы прибора лежит одно из положений физико-химической ме- ханики дисперсных систем П.А. Ребиндера [4].
Метод определения пластической прочности заключается в измерении величины погружения конуса в исследуемый материал, находящийся в форме, под действием постоянной нагрузки. Высота 50 мм и диаметр формы 70 мм. Такие размеры выбраны исходя из условий минимального влияния стенок и дна на величину определения пластической прочности [5].

Пластическая прочность PРmm (МПа) определялась через предельное напряжение сдвига т0 путем погружения конуса с пригрузом в исследуемую растворную смесь на определенную глубину под действием постоянной нагрузки. В результате этого площадь контакта конуса с материалом увеличивается, что приводит к уменьшению напряжения [6].

Для подбора составов растворов использована теория сокращенного планирования экспериментов [7]. Факторы, которые влияют на нього пластическую прочность следующие. $\mathrm{X}_{1}$ - процент содержания базальтовой фибры в следующих пределах: 3, 6 и 9\%. Х2 - процент содержания бентонита в следующих пределах: 5, 10 и 15 \%. Хз - процент содержания жидкого стекла в следующих пределах: 6, 12 и 18 \%. План эксперимента и уровни варьируемых технологических параметров сведены в Табл. 1.

\section{Результаты исследования}

При анализе влияния даннных добавок было построено кривые структурообразования 1-го состава с наименьшим процентом всех компонентов, 15-го состава с наибольшим процентом всех компонентов и 4-го состава с наибольшим процентом бентонита. Во всех составах применялся цемент 


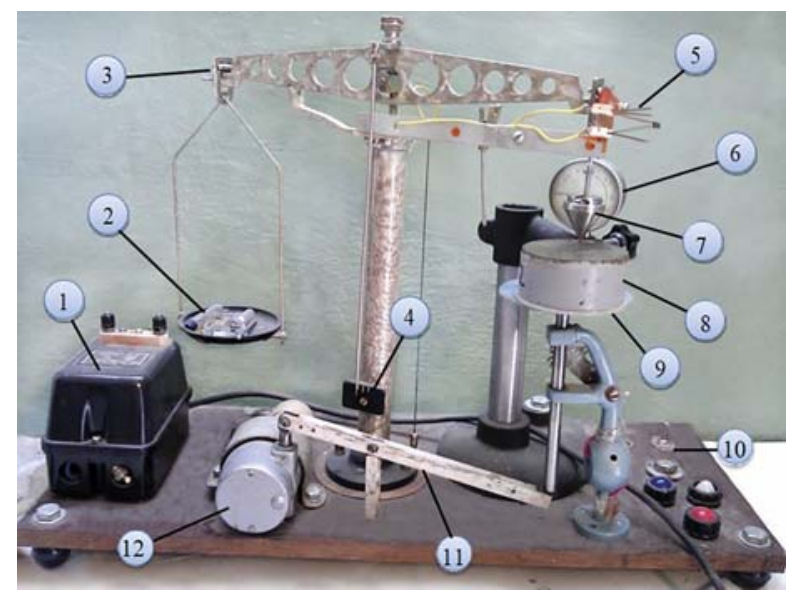

Рис. 1. Общий вид модернизированного пластометра Ребиндера: 1 - трансформаторный блок; 2 - навески для уравновешивания массы конуса с пригрузом; весовые «плечи»; 4 - шкала равновесия; 5 - контактные клеммы; 6 - индикатор погружения конуса; 7 - конус с пригрузом; 8 - форма с исследуемым материалом; 9 - автоматический столик; 10 - пульт управления столиком; 11 - рычажный механизм для опускания и поднятия столика;

12 - электропривод

ПЦ II АШ 400 с цементнопесчаным соотношением 1/3 и В/Ц составляло $1 \pm 0,2$.

На рисунке 2 приведен график набора пластической прочности 1-го состава с наименьшим процентом всех компонентов.

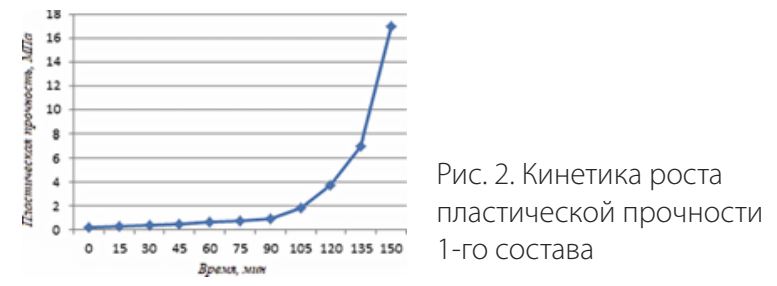

Из рисунка 2 видно, что происходит ускорение набора прочности по сравнению с исходным цементом без данных добавок. Примерно на 115-ой минуте твердения наблюдается интенсивный набор прочности раствора.

На рисунке 3 пиведен график набора пластической прочности 15-го состава с наибольшим процентом всех компонентов.

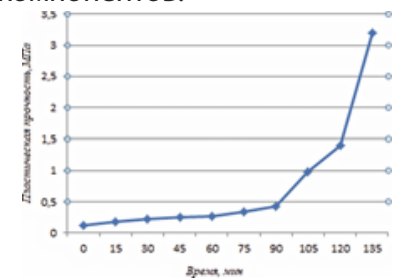

Рис. 3. Кинетика роста пластической прочности 15-го состава

Из рисунка 3 видно, что наибольший процент добавок также ускоряет набор прочности, но менее интенсивно, чем в первом случае. Только на 135 минуте наблюдается интенсивный набор прочности 15-го раствора.

На рисунке 4 приведен график набора пластической прочности 4-го состава с наибольшим процентом бентонита.

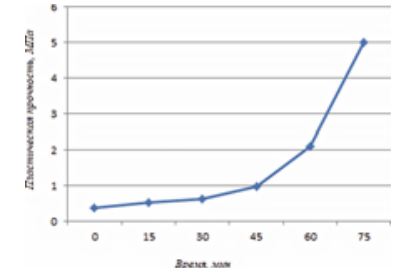

Рис. 4. Кинетика роста пластической прочности 4-го состава

Из рисунка 4 видно, что наибольшее ускорение набора прочности происходит с 4-ым раствором с наибольшим процентом бентонита, 15\% и наименьшим - фибры и жидкого стекла. Уже на 65 минуте происходит интенсивный набор прочности данного раствора.
План эксперимента и уровни варьируемых технологических параметров

\begin{tabular}{|c|c|c|c|c|c|c|}
\hline & & & & $X_{1}$ & $X_{2}$ & $\mathrm{X}_{3}$ \\
\hline № & $X_{1}$ & $X_{2}$ & $X_{3}$ & $\begin{array}{c}\text { Фибра, } \\
\%\end{array}$ & $\begin{array}{l}\text { Бенто- } \\
\text { нит, \% }\end{array}$ & $\begin{array}{c}\text { Жидкое } \\
\text { стекло, } \\
\%\end{array}$ \\
\hline 1 & -1 & -1 & -1 & 3 & 5 & 6 \\
\hline 2 & -1 & -1 & 1 & 3 & 5 & 18 \\
\hline 3 & -1 & 0 & 0 & 3 & 10 & 12 \\
\hline 4 & -1 & 1 & -1 & 2 & 15 & 6 \\
\hline 5 & -1 & 1 & 1 & 3 & 15 & 18 \\
\hline 6 & 0 & -1 & 0 & 6 & 5 & 12 \\
\hline 7 & 0 & 0 & -1 & 6 & 10 & 6 \\
\hline 8 & 0 & 0 & 0 & 6 & 10 & 12 \\
\hline 9 & 0 & 0 & 1 & 6 & 10 & 18 \\
\hline 10 & 0 & 1 & 0 & 6 & 15 & 12 \\
\hline 11 & 1 & -1 & -1 & 9 & 5 & 6 \\
\hline 12 & 1 & -1 & 1 & 9 & 5 & 18 \\
\hline 13 & 1 & 0 & 0 & 9 & 10 & 12 \\
\hline 14 & 1 & 1 & -1 & 9 & 15 & 6 \\
\hline 15 & 1 & 1 & 1 & 9 & 15 & 18 \\
\hline
\end{tabular}

\section{Выводы}

Проведен сравнительный анализ результатов исследования пластической прочности составов раствора для сооружения защитного грунтобетонного экрана под сооружением.

Наибольшый рост пластической прочности показал 4-ый раствор с наибольшим процентом бентонита и наименьшим - фибры и жидкого стекла. Такой состав рекомендуется для сооружения грунтобетонных экранов малой протяженности с большой интенсивностью производства работ.

\section{Литература:}

1. Зарубина Л.П., Защита территорий и строительных площадок от подтопления грунтовыми водами / М.: Инфра-Инженерия, 2017. 212с.

2. Менейлюк О.І., Петровський А.Ф., Борисов О.О., Кирилюк С.В., Розробка технології спорудження протифільтраційного екрану 3 використанням шнекового / Науковий вісник будівництва ХНУБА, №3. - Харків, 2018. с. 214-217.

3. Менейлюк О.І., Петровський А.Ф., Борисов О.О., Кирилюк С.В., Влаштування протифільтраційного екрана для захисту підземного простору від підтоплення / Вчені записки Таврійського національного університету імені В.І. Вернадського - журнал серії «Технічні науки», №1. - Київ, 2018. с. 176-180.

4. Ребиндер П.А., Поверхностные явления в дисперсных системах. Физико-химическая механика / М.: Наука, 1979. - 384 с.

5. Коваль С.В., Сапожников В.А., Гедулян С.И., Оценка эффективности добавок для монолитного бетона методом пластометрии / Вісник ОДАБА. - Одеса: Зовнішрекламсервіс, 2012. - Вип. №47. - С. 169-173.

6. Урьев Н. Б., Высококонцентрированные дисперсные системы / Н. Б. Урьев. - М.: Химия, 1980. - 320 с.

7. Вознесенский В. А., Ляшенко Т. В., Кривенко П. В., Методические рекомендации по применению экспериментально-статистических моделей для анализа и оптимизации состава, технологии и свойств композиционных материалов на основе щелоч ных вяжущих систем / ОГАСА, НИИВМ им. В. Д. Глуховского. - К.: 1996. - 106 с. 